\title{
Effect of Deposition Parameters on the Reactivity of Al/Ni Multilayer Thin Films
}

\author{
Ana Sofia Ramos $1, * \mathbb{*}$, Sónia Simões ${ }^{2,3}$ (D) Lukasz Maj ${ }^{4}$, Jerzy Morgiel ${ }^{4}$ and \\ Maria Teresa Vieira ${ }^{1}$ (D) \\ 1 Department of Mechanical Engineering, University Coimbra, CEMMPRE, R. Luís Reis Santos, \\ 3030-788 Coimbra, Portugal; teresa.vieira@dem.uc.pt \\ 2 Department of Metallurgical and Materials Engineering, University of Porto, R. Dr Roberto Frias, \\ 4200-465 Porto, Portugal; ssimoes@fe.up.pt \\ 3 LAETA/INEGI-Institute of Science and Innovation in Mechanical and Industrial Engineering, \\ R. Dr. Roberto Frias, 4200-465 Porto, Portugal \\ 4 Institute of Metallurgy and Materials Science, Polish Academy of Sciences, Reymonta 25, \\ 30-059 Cracow, Poland; l.maj@imim.pl (L.M.); j.morgiel@imim.pl (J.M.) \\ * Correspondence: sofia.ramos@dem.uc.pt; Tel.: +351-230790700
}

Received: 2 July 2020; Accepted: 20 July 2020; Published: 23 July 2020

\begin{abstract}
Nanoscale multilayers can be used as highly localized heat sources, making them attractive for several applications, in particular for joining and as igniters. Over the last decades, academia and industry have given particular emphasis to nanoscale multilayers from the $\mathrm{Ni}-\mathrm{Al}$ system. In this study, $\mathrm{Al} / \mathrm{Ni}(\mathrm{V})$ multilayer thin films with periods of nominally 25 and $50 \mathrm{~nm}$ (bilayer thickness) and near equiatomic average stoichiometry were produced by d.c. magnetron sputtering from $\mathrm{Al}$ (99.999\% pure) and $\mathrm{Ni}(93 \mathrm{wt} \% \mathrm{Ni}, 7 \mathrm{wt} \% \mathrm{~V}$ ) targets (vanadium was added to the $\mathrm{Ni}$ target to make it non-magnetic). Deposition parameters such as the substrate rotation speed and substrate bias were varied in order to evaluate their effect on the reactivity of the multilayers. The influence of in situ ion bombardment of the multilayer thin films was also studied. Phase identification was carried out by X-ray diffraction, while the microstructure was analyzed in detail by transmission electron microscopy, distinguishing alternating layers throughout the entire thickness of the films. Although the films mainly consist of $\mathrm{Al}$ - and Ni-rich layers, the presence of the $\mathrm{Al}_{3} \mathrm{Ni}$ intermetallic phase was detected, except in the multilayers produced with the ion gun switched on during the deposition process. The ion bombardment, as well as the increase of the substrate bias, promote some microstructural disorder and thus affect the multilayers' reactivity.
\end{abstract}

Keywords: Al/Ni; reactive multilayers; sputtering; ion bombardment; TEM; nanoindentation

\section{Introduction}

Reactive multilayer thin films/foils are composed of tens, hundreds, or thousands of alternating individual layers of at least two materials, having a large heat of formation and high adiabatic reaction temperature [1,2]. The thickness of the individual layers varies between few and several hundred nanometres, while the total thickness typically ranges from approximately 0.1 to $300 \mu \mathrm{m}$ [2]. The bilayered structure is repeated throughout the film/foil thickness. The negative enthalpy of mixing results in heat release once the reaction is initiated. For certain systems and designs, in particular for nanolayered reactive films/foils, the reaction can become self-sustained. After local ignition by an electrical or mechanical stimulus, the heat released promotes the reaction in adjacent regions, driving the reaction forward in a self-propagating wave [1]. The interest in reactive multilayers' self-propagating reactions stems from their potential utility to form intermetallic compounds in 
complex shapes, join heat-sensitive components, and ignite secondary reactions [3]. Among these applications, the use of $\mathrm{Al} / \mathrm{Ni}$ foils as highly localized heat sources capable of melting solder/brazing alloys and thus promoting joining is relevant [4-7]. It should be noted that these multilayers have been used as free-standing foils, because otherwise, the heat released upon reaction is dissipated throughout the substrate material, hindering the reaction to become self-sustained. Rabinovich et al. [8] developed a $2 \mathrm{D}$ model to determine the proper conditions for the self-propagation of the $\mathrm{Ni}+\mathrm{Al}$ reaction in nanolayered $\mathrm{Al} / \mathrm{Ni}$ films. Whatever the modulation period ( $\Lambda$, bilayer thickness), it was concluded that the reaction could self-propagate only in multilayer films with a sufficiently large number of layers. Nevertheless, it should be noted that the occurrence of self-propagating reactions in multilayer-coated materials would enlarge the field of application of these reactive coatings/films. For this purpose, the study of the reactivity of nanolayered films is crucial. Although alternating layers of $\mathrm{Al}$ and $\mathrm{Ni}$ constitute the most extensively investigated reactive multilayer system, its reactivity still needs to be improved to promote self-propagation in $\mathrm{Al} / \mathrm{Ni}$ films (a few micrometers thick) on a substrate. For this purpose, the effect of intermixing must be minimized. During the deposition process, intermixing occurs at the interfaces, resulting in the formation of solid solutions, intermetallic, or amorphous phases, which will influence the multilayer reactivity. The effect of intermixing on self-propagating reactions in $\mathrm{Al} / \mathrm{Ni}$ nanolayered foils has been the focus of several papers $[9,10]$. The velocity of the reaction front and the maximum temperature attained in self-propagating reactions strongly depend on the degree of intermixing. In a recent paper, the effect of post-deposition ion beam irradiation on the structure and reactivity of sputter-deposited $\mathrm{Al} / \mathrm{Ni}$ multilayers with a total thickness of $10 \mu \mathrm{m}$ was investigated [11]. Short irradiation times led to lower ignition temperatures and shorter ignition delay times, while the opposite was observed for long exposures. Therefore, high-energy ion irradiation can be an effective tool for tailoring the reactivity of nanostructured $\mathrm{Al} / \mathrm{Ni}$ multilayers. Numerical and experimental investigations were also carried out by Politano et al. [12] to study the reactivity of $\mathrm{Al} / \mathrm{Ni}$ multilayer foils, allowing the rational design of these energetic materials.

In this context, $\mathrm{Al} / \mathrm{Ni}(\mathrm{V})$ multilayer thin films with a nanometric period and near equiatomic average stoichiometry were produced by d.c. magnetron sputtering. The substrate bias was varied in order to study its effect on the reactivity of the multilayers, as well as the effect of in situ ion bombardment during the deposition process. The influence of the deposition parameters on the microstructure and hardness of the multilayer thin films was studied by transmission electron microscopy (TEM) and nanoindentation, respectively.

\section{Materials and Methods}

\subsection{Deposition Technique}

$\mathrm{Al} / \mathrm{Ni}(\mathrm{V})$ multilayer thin films were deposited onto silicon and glass substrates by d.c. magnetron sputtering from two targets [13]. The desired average chemical composition is approximately 45 at.\% $\mathrm{Al}, 50$ at. $\% \mathrm{Ni}$, and 5 at. $\% \mathrm{~V}$. For this purpose, the Al layers must be thicker than the Ni ones. A stainless steel sheet shield was placed between the two sputtering targets to minimize cross-contamination of the targets and avoid the mixing of atomic fluxes. To minimize surface oxidation, Ni was selected as the top layer. Considering the $\mathrm{Al}-\mathrm{Ni}$ system, $\mathrm{Al}$ was selected for the bottom layer to improve the adhesion of the coatings to the substrate, because the adhesion of $\mathrm{Ni}$ to $\mathrm{Si}$ and glass substrates is worse. The sputtering equipment has an ion gun with an independent power supply, which is usually used to clean the substrates before the deposition of the films. In this work, multilayer thin films were prepared with the ion gun switched on during the sputtering process, in which the growing films were in situ ion bombarded by $\mathrm{Ar}^{+}$. Regarding the substrate bias, the reference value was $-40 \mathrm{~V}$, while for comparison purposes, films were prepared using $-80 \mathrm{~V}$ bias. Multilayer thin films with 25 and $50 \mathrm{~nm}$ nominal periods were produced by varying the substrate rotation speed. In all cases, the total thickness was close to $2.5-3.0 \mu \mathrm{m}$. The modulation period can easily be estimated by dividing the total thickness 
by the deposition time multiplied by the number of rotations per time unit. The total thickness was measured by profilometry. The multilayer thin films prepared are summarized in Table 1.

Table 1. Al/Ni (V) multilayer thin films deposited by magnetron sputtering.

\begin{tabular}{ccccccc}
\hline Designation & $\begin{array}{c}\text { Deposition } \\
\text { Time (min) }\end{array}$ & $\begin{array}{c}\text { Rotation } \\
\text { Speed (rpm) }\end{array}$ & $\begin{array}{c}\text { Substrate } \\
\text { Bias (V) }\end{array}$ & Ion Gun & $\begin{array}{c}\text { Total Thickness } \\
*(\mathbf{n m})\end{array}$ & $\begin{array}{c}\text { Estimated } \\
\text { Period }(\mathbf{n m})\end{array}$ \\
\hline$\Lambda=25$ & 31 & 3.5 & -40 & OFF & 2700 & 25 \\
$\Lambda=50$ & 32 & 2 & -40 & OFF & 2900 & 45 \\
$V_{\mathrm{S}}=-80$ & 31 & 3.5 & -80 & OFF & 2700 & 25 \\
Ion Gun & 33 & 3 & -40 & ON & 2500 & 25 \\
\hline \multicolumn{7}{c}{$*$ measured by profilometry $( \pm 50 \mathrm{~nm})}$.
\end{tabular}

\subsection{Characterization Techniques}

The nanolayered films were analyzed by $\mathrm{X}$-ray diffraction $(\mathrm{XRD})$ using $\mathrm{Cu} \mathrm{K} \alpha$ radiation $(\lambda=0.154060 \mathrm{~nm})$ operated at $45 \mathrm{kV}$ and $40 \mathrm{~mA}$, with a parallel beam at an approximately $0.2 \mathrm{~min}^{-1}$ scanning speed (PANalytical X'Pert PRO, Almelo, The Netherlands). A hybrid monochromator was used, which is able to convert the divergent $\mathrm{X}$-ray beam into a quasi-parallel beam with pure $\mathrm{K} \alpha 1$ radiation. Symmetric $\theta-2 \theta$ geometry was used to study the influence of the deposition parameters on the as-deposited crystalline phases. The $\mathrm{Al}$ (111) XRD peak was fitted by using a pseudo-Voigt function to calculate the full width at half maximum (FWHM) and the peak position (20), and then estimate the crystallite size by Scherrer's equation. The objective is to compare the crystallite size of the multilayer films under study.

Detailed microstructural analysis was performed by transmission electron microscopy (TEM) in bright-field (BF), scanning-transmission (STEM), and high-resolution (HRTEM) modes (FEI Tecnai G2 FEG SuperTWIN, Eindhoven, The Netherlands). The TEM microscope is equipped with high-angular annular dark field (HAADF) and EDAX detectors for STEM and energy-dispersive spectroscopy (EDS) investigations, respectively. Thin foils for TEM were prepared by means of an FEI Quanta 3D 200 Dual Beam Focused Ion Beam (FIB) equipped with a Omniprobe lift-out system.

The hardness of the multilayer thin films was evaluated by depth-sensing indentation technique (Micro Materials NanoTest, Wrexham, UK) using a Berkovich diamond indenter. A $5 \mathrm{mN}$ load was applied, which gave rise to indentation depths lower than $1 / 10$ of the total thickness, and thus avoiding the influence of the silicon substrate. For each film, a minimum of 35 hardness measurements was carried out. Fused quartz was used as a reference material to determine the Berkovich tip area function.

\section{Results and Discussion}

\subsection{Phase Analysis}

X-ray diffractograms of the $\mathrm{Al} / \mathrm{Ni}(\mathrm{V})$ multilayer thin films (Figure 1) reveal $\mathrm{Al}$ and Ni face-centered cubic (fcc) phases. Due to the presence of $\mathrm{Ni}(\mathrm{Al})$ in the $\mathrm{Al}(\mathrm{Ni})$ lattice, the $\mathrm{Al}(\mathrm{Ni})$ peaks are shifted to higher (lower) angles than those in the (ICDD) [14] diffraction cards. A preferential orientation along the (111) XRD plane is observed, which is typical for sputtered fcc metals [15]. In the as-deposited thin films, no intermetallic phases can be detected by XRD. The increase of the modulation period, which was achieved by using a lower rotation speed, gives rise to more intense and narrower $\mathrm{Al}$ and Ni peaks. The use of a higher substrate bias voltage results in a higher intensity of the $\mathrm{Ni}$ (111) XRD peak, while the in situ bombardment of the growing films with $\mathrm{Ar}^{+}$ions gives rise to a slight decrease in the Ni (111) peak intensity. 


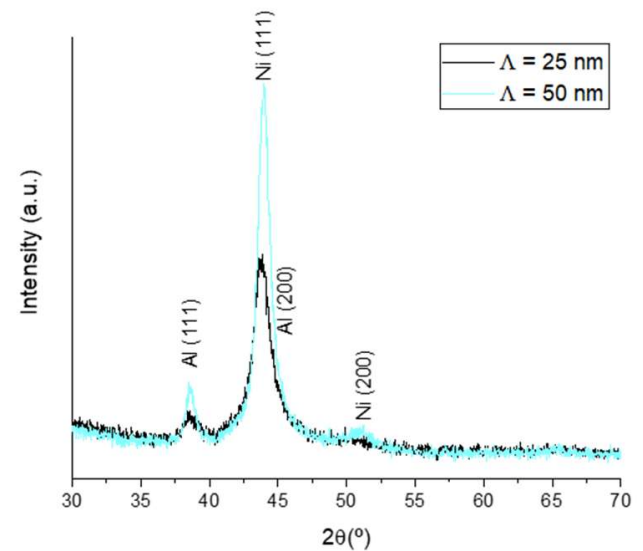

(a)

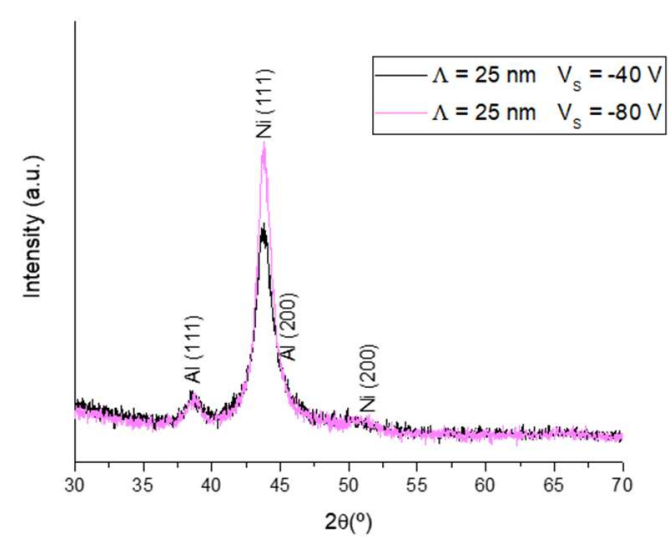

(b)

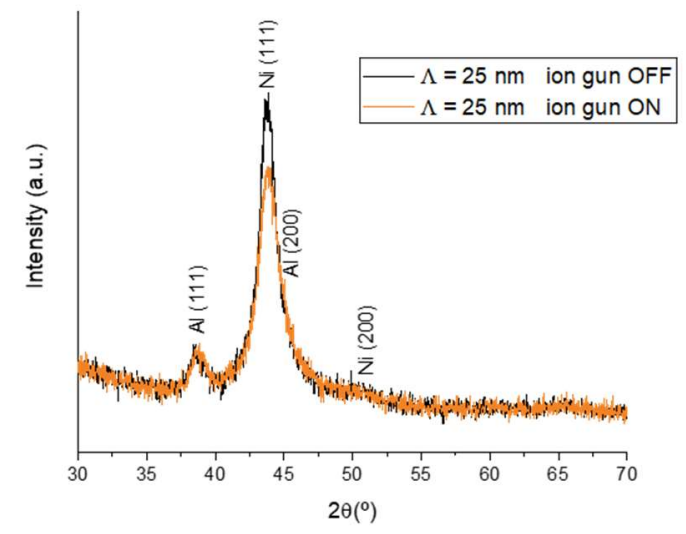

(c)

Figure 1. X-ray diffractograms of $\mathrm{Al} / \mathrm{Ni}(\mathrm{V})$ multilayer films. (a) Modulation period $(\Lambda)$; (b) Substrate bias $\left(V_{\mathrm{S}}\right)$; (c) Ion gun.

The $\mathrm{Al}$ (111) XRD peak was selected to determine the crystallite size by the Scherrer equation. For this purpose, a fitting using a pseudo-Voigt function was carried out. All the films have nanometric crystallites, whose size is dependent on the individual layer thickness, and thus on the modulation period, as shown in Figure 2. In fact, the highest crystallite size is obtained for the multilayer film with an estimated period of $45 \mathrm{~nm}$, while the other films have similar values. According to these results, it seems that the crystallite size is mainly dependent on the individual layer thickness. The increase of the grain size with the multilayer period has also been seen in other works $[16,17]$.

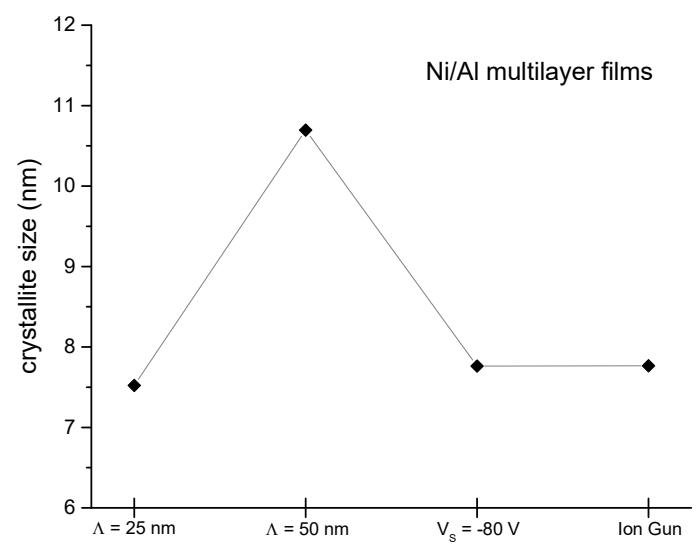

Figure 2. Crystalline size of the $\mathrm{Al} / \mathrm{Ni}(\mathrm{V})$ multilayer films under study. 


\subsection{Microstructure}

BF-TEM and HAADF-STEM images of the multilayer thin film with a $25 \mathrm{~nm}$ period $\left(V_{\mathrm{S}}=-40 \mathrm{~V}\right.$, ion gun off) are shown in Figure 3, revealing its nanolayered structure throughout the whole thickness. In the BF images, the Al-rich layers correspond to the light gray layers and the Ni-rich layers correspond to the dark gray layers, while in STEM mode, it is the opposite. As a result of the sputtering process, pseudo-columnar cross-section morphology can be observed (Figure 3). Assessment of the multilayer period using TEM can be done either locally (measuring individual layers) or averaged from a larger area (covering several nanolayers). The former is performed on a near perfect area similar to the one represented by the continuous short red line in Figure 3b, giving a value of $25.1 \mathrm{~nm}$. The other approach involves Fourier transform from the larger red dot square area (Figure $3 b$ ). In this case, the intensity profile gives a period of approximately $27 \mathrm{~nm}$, which is larger than the previous one because some nanolayers are not perfectly aligned with the beam.

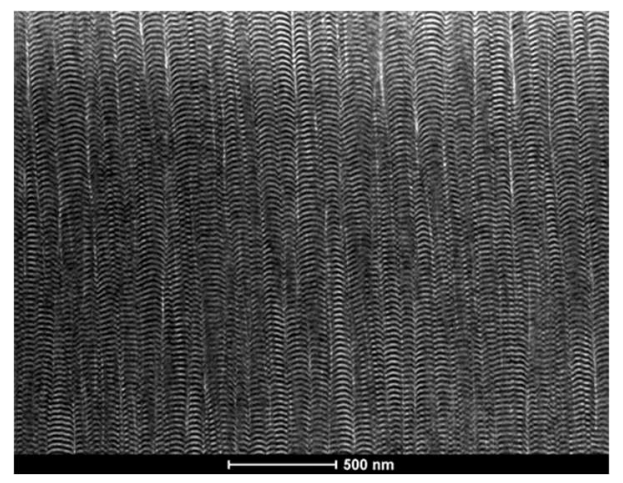

(a)

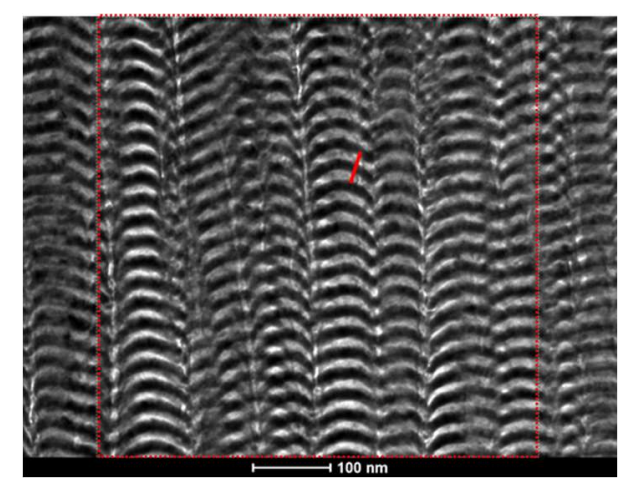

(b)

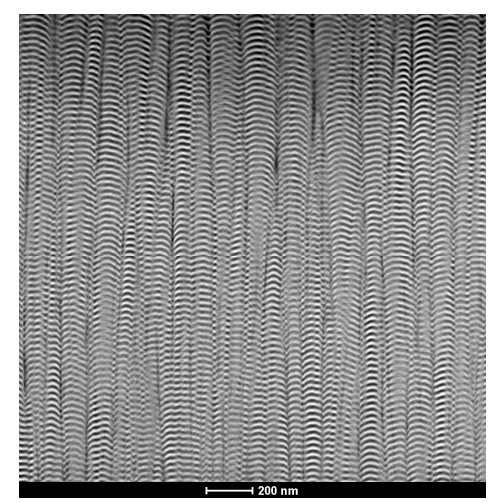

(c)

Figure 3. TEM cross-section micrographs of the $\mathrm{Al} / \mathrm{Ni}(\mathrm{V})$ film with $\Lambda=25 \mathrm{~nm}\left(V_{\mathrm{S}}=-40 \mathrm{~V}\right.$, ion gun off): (a) bright-field (BF) image at lower magnification; (b) BF image at higher magnification; (c) STEM image.

For comparison purposes, in Figure 4, the BF-TEM images of the other films are presented. The period of the film prepared using a lower rotation speed, estimated as $45 \mathrm{~nm}$ (Table 1), can be confirmed from Figure 4a. According to the BF-TEM image, the period is about $55 \mathrm{~nm}$, which is slightly higher than the desired value $(50 \mathrm{~nm})$. The effect of increasing the substrate bias can be observed by comparing Figure $4 \mathrm{~b}$ with Figure 3 , while the influence of the in situ ion bombardment is highlighted in Figure $4 \mathrm{c}$ when compared to Figure 3. Both the increase of the substrate bias and the use of the ion gun result in the increase of "imperfections"/defects in the layered structure, as illustrated in Figure $4 b, c$, respectively. In fact, in Figure $4 b, c$, there are regions where the individual layers cannot be distinguished. In Figure 5, selected area electron diffraction (SAED) patterns of $25 \mathrm{~nm}$ period films, with the ion gun off and on, are presented $\left(V_{S}=-40 \mathrm{~V}\right)$. The SAED pattern of the film with $-80 \mathrm{~V}$ substrate bias is similar (not shown). Indexation of the diffraction rings confirms the presence of $\mathrm{Ni}$ 
and $\mathrm{Al}$ phases. In agreement with the XRD results, no intermetallic phases are detected by SAED. According to these results, the multilayer thin films are composed of Ni-rich and Al-rich alternated layers. However, due to the occurrence of intermixing during the sputtering process, there is always $\mathrm{Ni}$ in the Al layers and vice versa.

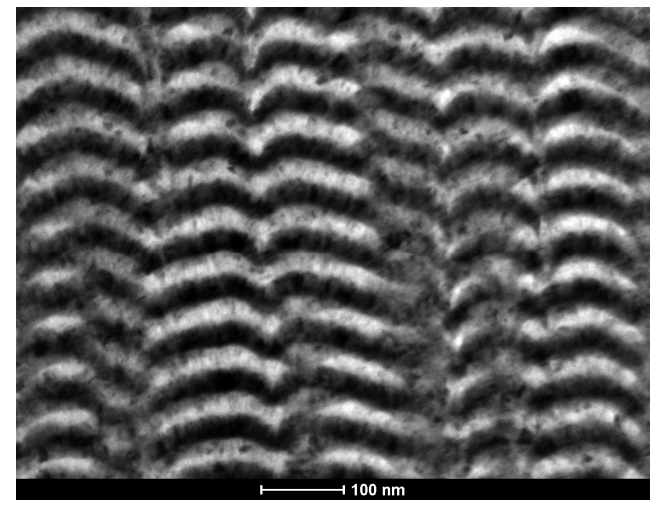

(a)

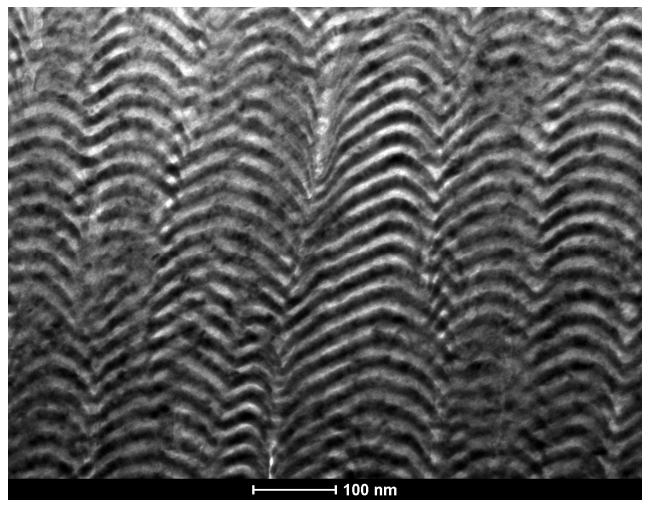

(b)

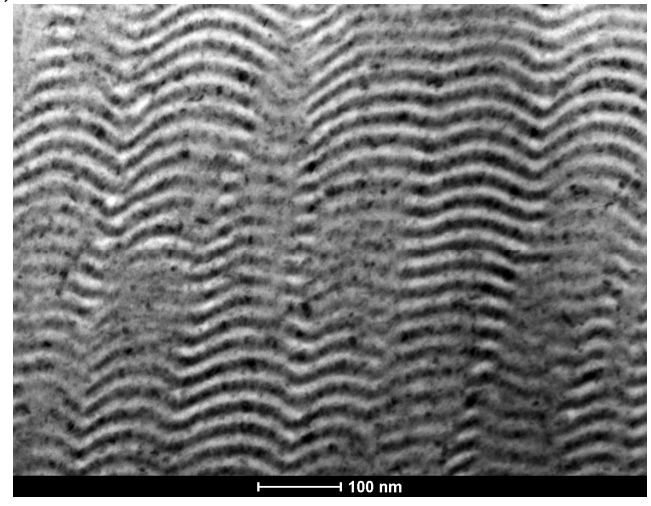

(c)

Figure 4. BF TEM cross-section micrographs of $\mathrm{Al} / \mathrm{Ni}(\mathrm{V})$ films: (a) $\Lambda=50 \mathrm{~nm}$; (b) $V_{\mathrm{S}}=-80 \mathrm{~V}$; (c) ion gun on.

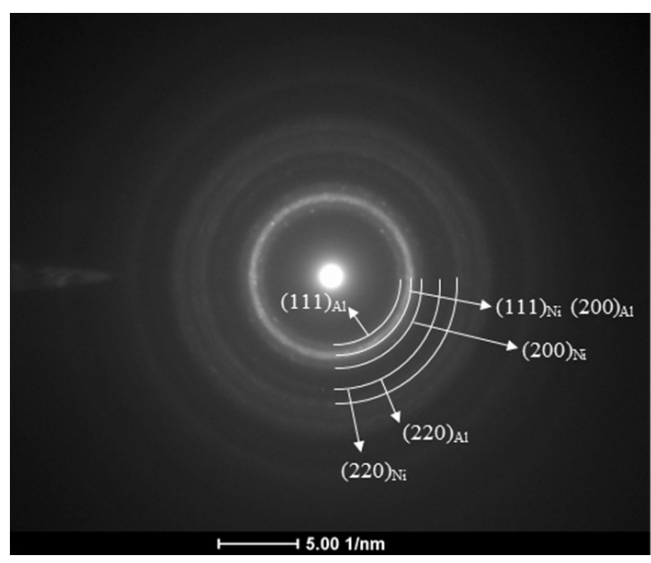

(a)

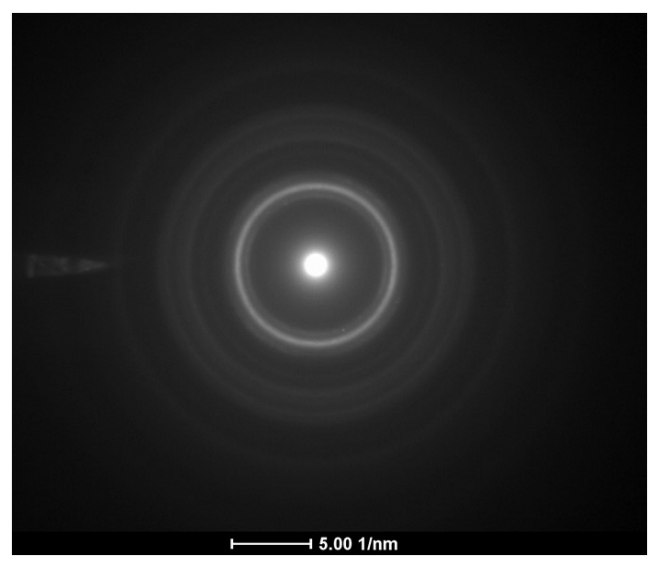

(b)

Figure 5. Selected area electron diffraction (SAED) pattern of $\mathrm{Al} / \mathrm{Ni}$ (V) films with $\Lambda=25 \mathrm{~nm}$ : (a) ion gun off; (b) ion gun on. 
TEM/EDS measurements were carried out to provide qualitative information regarding the intermixing in the $\mathrm{Al} / \mathrm{Ni}(\mathrm{V})$ multilayer thin films under study. TEM/EDS analyses on the $25 \mathrm{~nm}$ period multilayer $\left(V_{S}=-40 \mathrm{~V}\right.$, ion gun off) reveal Ni contents on the Al-rich layers as high as 40 at.\%. The $\mathrm{Al}$ content on the Ni-rich layers is below 30 at.\%, which is in agreement with its lower diffusivity when compared to Ni. The activation energy $\left(E_{\mathrm{a}}\right)$ for the diffusion of $\mathrm{Al}$ in Ni is approximately $280 \mathrm{~kJ} / \mathrm{mol}$, while $E_{\mathrm{a}}$ for the diffusion of $\mathrm{Ni}$ in $\mathrm{Al}$ is close to $154 \mathrm{~kJ} / \mathrm{mol}$ [18]. As expected, the thicker individual layers of the multilayer film with a nominal period of $50 \mathrm{~nm}$ result in less intermixing: up to 25 at.\% of $\mathrm{Ni}$ can be found in the $\mathrm{Al}$ layers and 22 at.\% of $\mathrm{Al}$ in the Ni layers. The increase of the substrate bias is responsible for a significant increase of the $\mathrm{Al}$ content on the Ni-rich layers ( $>45$ at.\%), while the amount of $\mathrm{Ni}$ in the Al-rich layers remains similar. The ion bombardment of the growing film only slightly increases the amount of intermixing. It should be noted that the applied $1 \mathrm{~nm}$ beam spot (understood as full width at half maximum of the section of its overall intensity) does not guarantee the undisturbed estimate of the intermixing, as neither the beam broadening nor the fluorescence were taken into account. Therefore, the given $\mathrm{Ni}$ and $\mathrm{Al}$ contents mean that the intermixing is not higher than the values indicated. The presence of vanadium is also detected by EDS. The V content varies between approximately 3 and 6 at.\%, except for the higher period multilayer, where, as expected, the amount of $\mathrm{V}$ in the Al-rich layers is lower.

To study the microstructure of the multilayer films in more detail, HRTEM analysis were carried out. The Al- and Ni-rich phases can be distinguished, allowing the period and the Al:Ni individual layer thickness ratio to be confirmed. The HRTEM analysis also provides valuable information regarding the interfaces. During the sputtering process, a pre-mixed zone forms at the multilayer interfaces, with the formation of solid solutions and/or metastable intermetallic or amorphous phases. According to the HRTEM images of Figure 6, the period of the reference Ni/Ti multilayer thin film is close to $25 \mathrm{~nm}$, as desired. The $\mathrm{Al}$ layers are thicker than the Ni ones, as required in order to obtain the desired average equiatomic chemical composition (Section 2.1). No intermetallic phases were identified near the interfaces. However, besides the $\mathrm{Ni}$ and $\mathrm{Al}$ fcc phases, by fast Fourier transform (FFT) of the HRTEM images, the presence of the $\mathrm{Al}_{3} \mathrm{Ni}$ phase is also detected, as shown in Figure 6 . This is an orthorhombic phase, which was previously reported in the literature as the first phase to form under the heat treatment of $\mathrm{Al} / \mathrm{Ni}$ multilayers $[19,20]$. The $\mathrm{Al}_{3} \mathrm{Ni}$ intermetallic phase is hard and fragile. In Figure $6 \mathrm{c}$, an $\mathrm{Al}_{3} \mathrm{Ni}$ grain can be observed in the $\mathrm{Al}$ layer. Apart from the individual layer thickness, no significant differences were observed on the HRTEM images of the highest period multilayer thin film (Figure 7). The presence of the $\mathrm{Al}_{3} \mathrm{Ni}$ phase was also confirmed by FFT, although in this case, the effect of intermixing is lower than in the short period multilayers. Considering the $\mathrm{Al}$ and $\mathrm{Ni}$ individual layer thicknesses, the modulation period is $55 \mathrm{~nm}$, which is slightly higher than the nominal value and coincides with the value obtained from BF TEM images.

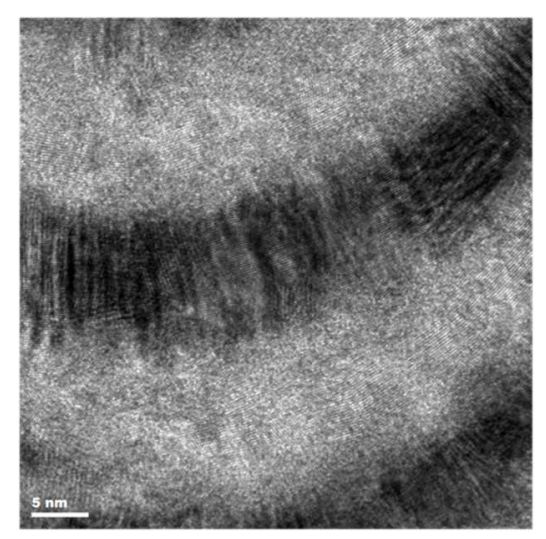

(a)

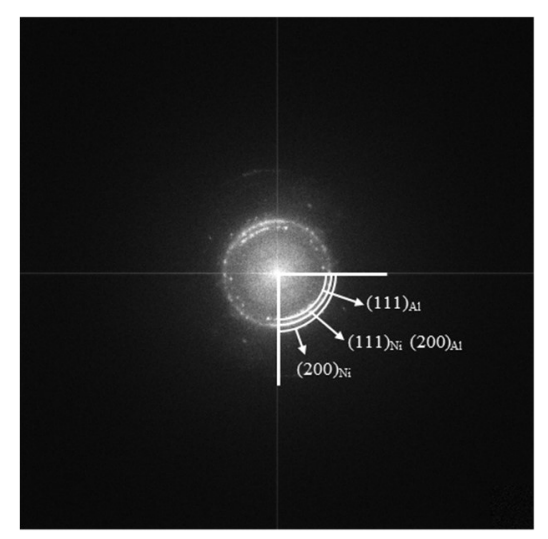

(b)

Figure 6. Cont. 


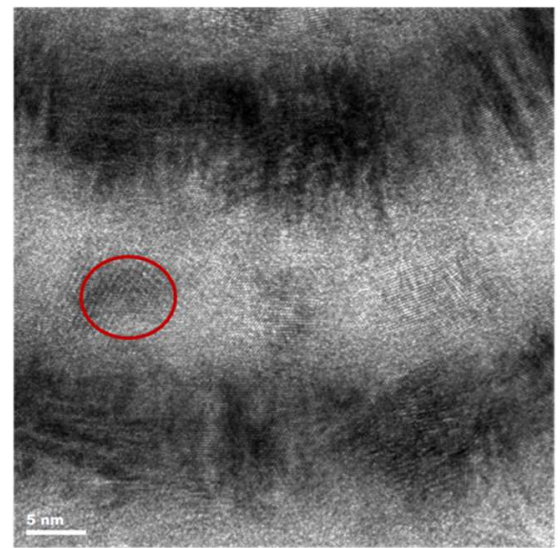

(c)

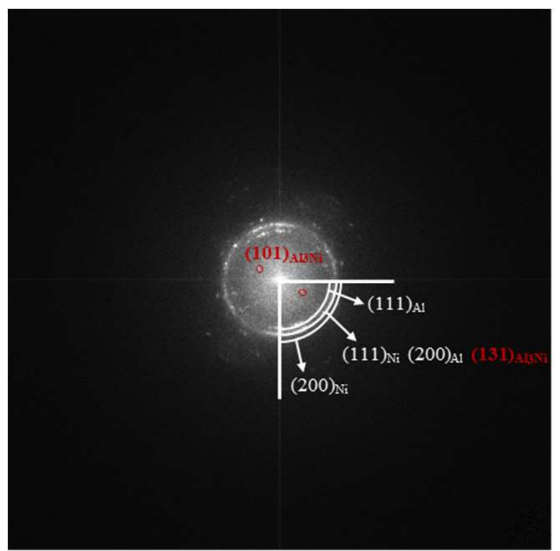

(d)

Figure 6. (a,c) High-resolution TEM (HRTEM) images; and (b,d) respective fast Fourier transform (FFT) in two regions of the $\mathrm{Al} / \mathrm{Ni}(\mathrm{V})$ film with $\Lambda=25 \mathrm{~nm}\left(V_{\mathrm{S}}=-40 \mathrm{~V}\right.$, ion gun off).

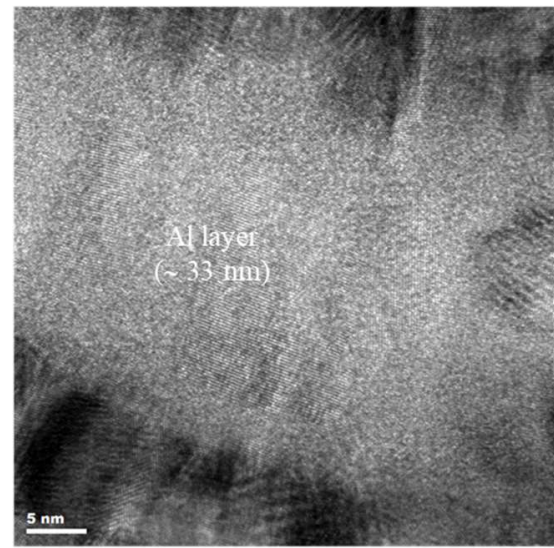

(a)

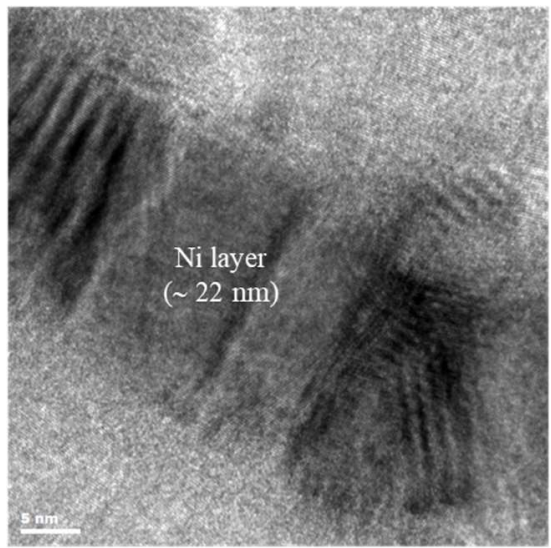

(b)

Figure 7. HRTEM images of the $\mathrm{Al} / \mathrm{Ni}(\mathrm{V})$ film with $\Lambda=50 \mathrm{~nm}\left(V_{\mathrm{S}}=-40 \mathrm{~V}\right.$, ion gun off). (a) $\mathrm{Al}$ layer highlighted; (b) Ni layer highlighted.

The influence of the substrate bias and the ion bombardment are highlighted in Figure 8. The increase of the substrate bias seems to promote some microstructural disorder, which is even more notorious when the films are in situ ion bombarded during the deposition process. Increasing the bombardment of the growing films, either by using a $-80 \mathrm{~V}$ bias, or by keeping the ion gun on during the deposition process, promotes defect formation in crystal lattice (dislocations). Nevertheless, the individual layers are still distinguishable with $\mathrm{Ni}$ and $\mathrm{Al}$ fcc phases always indexed after FFT. Although, to a lesser extent, the $\mathrm{Al}_{3} \mathrm{Ni}$ phase can be found in the films prepared using $V_{\mathrm{S}}=-80 \mathrm{~V}$. On the contrary, this intermetallic phase was never observed by FFT of the HRTEM images of the multilayer thin films deposited with the ion gun switched on.

The absence of the $\mathrm{Al}_{3} \mathrm{Ni}$ phase constitutes a promising result, not only due to its fragility, but because its presence reduces the driving force for the $\mathrm{Ni}+\mathrm{Al}$ self-propagating exothermic reaction and thus the multilayers' reactivity. This result is in agreement with the work of Manukyan et al. [11], who concluded that short high-energy post-deposition irradiation by ${ }^{12} \mathrm{C}^{4+}$ ions leads to a significant enhancement of reactivity of $\mathrm{Al} / \mathrm{Ni}$ multilayer films with $\Lambda=65 \mathrm{~nm}$. 


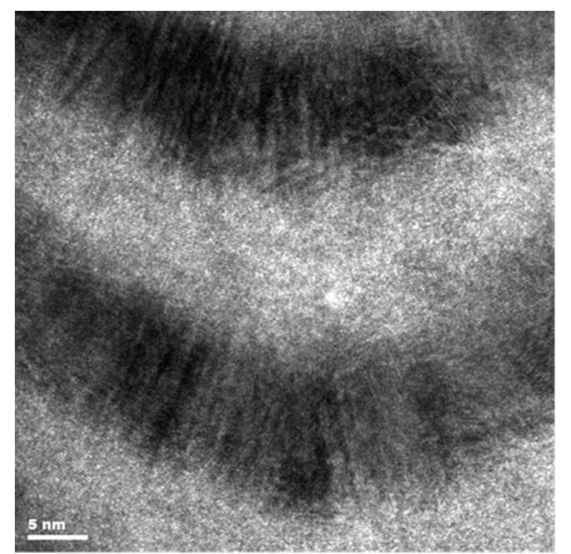

(a)

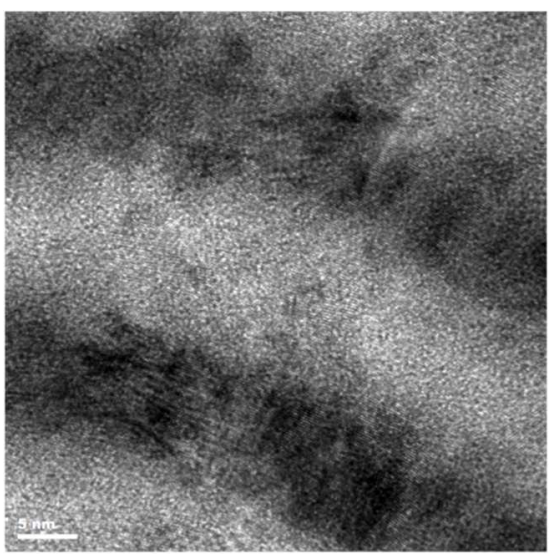

(b)

Figure 8. HRTEM images of the $\mathrm{Al} / \mathrm{Ni}(\mathrm{V})$ films with $\Lambda=25 \mathrm{~nm}$ : (a) $V_{\mathrm{S}}=-80 \mathrm{~V}$ (ion gun off); (b) ion gun on $\left(V_{\mathrm{S}}=-40 \mathrm{~V}\right)$.

\subsection{Hardness}

Typically, the hardness of multilayer thin films is higher than the values resulting from a simple rule of mixtures, this hardness enhancement being more pronounced for nanomultilayers. As expected, the hardness of the $\mathrm{Al} / \mathrm{Ni}(\mathrm{V})$ multilayer thin films increases as the modulation period decreases (Figure 9a). The individual layer thickness limits the grain size; the lower the grain size, the higher the hardness. This behavior is observed in other metallic multilayer systems, namely in $\mathrm{Ag} / \mathrm{Ni}$ nanomultilayers with periods between 8 and $100 \mathrm{~nm}$ [21]. As can be seen in Figure 9b, the increase of the substrate bias does not seem to significantly influence the hardness, while the use of the ion gun during the deposition process is responsible for a hardness increase. This increase is due to the microstructural changes resulting from the ion bombardment of the growing $\mathrm{Al} / \mathrm{Ni}(\mathrm{V})$ thin films observed in the previous section. The ion bombardment promotes the formation of denser deposits, i.e., having less porosity in between columnar grains and increasing the hardness of the multilayer thin films.

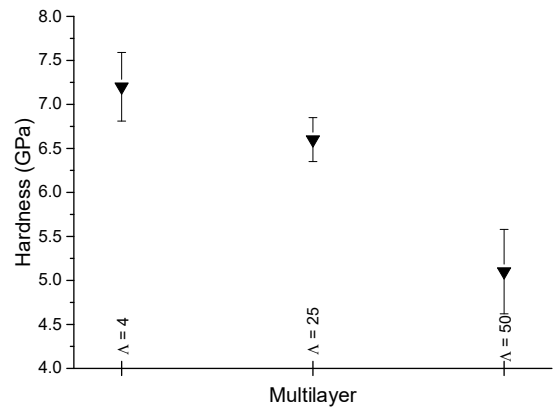

(a)

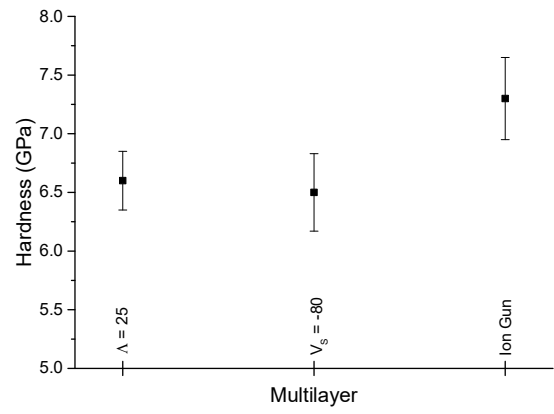

(b)

Figure 9. Hardness of the $\mathrm{Al} / \mathrm{Ni}(\mathrm{V})$ multilayer thin films: (a) influence of the period; (b) influence of the substrate bias and ion bombardment.

\section{Conclusions}

$\mathrm{Al} / \mathrm{Ni}(\mathrm{V})$ multilayers thin films with nanometric periods were prepared by magnetron sputtering using different deposition parameters in order to study their influence on the (micro)structure of the reactive thin films. The presence of $\mathrm{Ni}$ - and Al-rich phases was confirmed by XRD, but the presence of (undesired) intermetallic phases was only detected by FFT of HRTEM images. Both the 
increase of the substrate bias and the in situ ion bombardment of the growing films promote some microstructural disorder and simultaneously decrease the formation of the $\mathrm{Al}_{3} \mathrm{Ni}$ intermetallic phase in the as-deposited films, these effects being more pronounced when using the ion gun switched on during the sputtering process. In fact, the presence of the $\mathrm{Al}_{3} \mathrm{Ni}$ phase was not detected in the $\mathrm{Al} / \mathrm{Ni}$ (V) films that were in situ ion bombarded during the deposition process. The microstructural changes observed in this case are responsible for a hardness increase of the multilayer thin film.

In conclusion, by changing the sputtering parameters and by keeping the equipment ion gun switched on during the deposition of $\mathrm{Al} / \mathrm{Ni}(\mathrm{V})$ multilayer thin films, it is possible to adjust their reactivity and thus design these energetic materials according to the envisaged applications.

Author Contributions: The work was conceived and designed by A.S.R. and M.T.V.; A.S.R. prepared the multilayer thin films and performed the XRD and nanoindentation experiments; J.M. and L.M. carried out the TEM observations and analyzed the data together with S.S. All the authors participated in the discussion of the results. A.S.R. wrote the paper with contributions from all the other authors. All authors have read and agreed to the published version of the manuscript.

Funding: This work was financially supported by: Project PTDC/CTM-CTM/29101/2017-POCI-01-0145-FEDER-029101 funded by FEDER funds through COMPETE2020-Programa Operacional Competitividade e Internacionalização (POCI) and by national funds (PIDDAC) through FCT/MCTES. This research was also supported by FEDER funds through the program COMPETE-Programa Operacional Factores de Competitividade, and by national funds through FCT-Fundação para a Ciência e a Tecnologia, under the project UIDB/EMS/00285/2020.

Conflicts of Interest: The authors declare no conflict of interest.

\section{References}

1. Weihs, T.P. Fabrication and characterization of reactive multilayer foils and films. In Metallic Films for Electronic, Optical and Magnetic Applications—Structure, Processing and Properties, 1st ed.; Barmak, K., Coffey, K., Eds.; Woodhead Publishing Limited: Cambridge, UK, 2014; Volume 3, pp. 160-242. ISBN 978-0-85709-057-7.

2. Adams, D.P. Reactive multilayers fabricated by vapor deposition: A critical review. Thin Solid Films 2015, 576, 98-128. [CrossRef]

3. Besnoin, E.; Cerutti, S.; Knio, O.M. Effect of reactant and product melting on self-propagating reactions in multilayer foils. J. Appl. Phys. 2002, 92, 5474-5481. [CrossRef]

4. Wang, J.; Besnoin, E.; Duckham, A.; Spey, S.J.; Reiss, M.E.; Knio, O.M.; Powers, M.; Whitener, M.; Weihs, T.P. Room-temperature soldering with nanostructured foils. Appl. Phys. Lett. 2003, 83, 3987-3989. [CrossRef]

5. Duckam, A.; Spey, S.J.; Wang, J.; Reiss, M.E.; Weihs, T.P.; Besnoin, E.; Knio, O.M. Reactive nanostructured foil used as heat source for joining titanium. J. Appl. Phys. 2004, 96, 2336-2342. [CrossRef]

6. Qiu, X.; Wang, J. Bonding silicon wafers with reactive multilayer foils. Sensor Actuat. A 2008, 141, 476-481. [CrossRef]

7. Cao, J.; Feng, J.C.; Li, Z.R. Microstructure and fracture properties of reaction-assisted diffusion bonding of TiAl intermetallic with Al/Ni multilayer foils. J. Alloys Compd. 2008, 466, 363-367. [CrossRef]

8. Rabinovich, O.S.; Grinchuk, P.S.; Andreev, A.M.; Khina, B.B. Conditions for combustion synthesis in nanosized Ni-Al films on a substrate. Phys. Rev. B 2007, 392, 272-280. [CrossRef]

9. Gavens, A.J.; Van Heerden, D.; Mann, A.B.; Reiss, M.E.; Weihs, T.P. Effect of intermixing on self-propagating exothermic reactions in Al/Ni nanolaminate foils. J. Appl. Phys. 2000, 87, 1255-1263. [CrossRef]

10. Swain, M.; Singh, S.; Basu, S.; Gupta, M. Effect of interface morphology on intermetallics formation upon annealing of Ni-Al multilayer. J. Alloys Compd. 2013, 484, 257-261. [CrossRef]

11. Manukyan, K.V.; Tan, W.; de Boer, R.J.; Stech, E.J.; Aprahamian, A.; Wiescher, M.; Rouvimov, S.; Overdeep, K.R.; Shuck, C.E.; Weihs, T.P.; et al. Irradiation-enhanced reactivity of multilayer Al/Ni nanomaterials. ACS Appl. Mater. Interfaces 2015, 7, 11272-11279. [CrossRef] [PubMed]

12. Politano, O.; Baras, F.; Mukasyan, A.S.; Vadchenko, S.G.; Rogachev, A.S. Microstructure development during $\mathrm{NiAl}$ intermetallic synthesis in reactive Ni-Al nanolayers; Numerical investigations vs. TEM observations. Surf. Coat. Technol. 2013, 215, 485-492. [CrossRef]

13. Ramos, A.S.; Maj, L.; Morgiel, J.; Vieira, M.T. Coating of Tungsten Wire with Ni/Al Multilayers for Self-Healing Applications. Metals 2017, 574, 574. [CrossRef] 
14. ICCD-International Centre for Diffraction Data. Cards 4-0787 and 4-0850 h. Available online: https: //www.icdd.com/ (accessed on 2 July 2020).

15. Edelstein, A.S.; Everett, R.K.; Richardson, G.Y.; Qadri, S.B.; Altman, E.I.; Foley, J.C.; Perepezko, J.H. Intermetallic phase formation during annealing of Al/Ni multilayers. J. Appl. Phys. 1994, 76, 7850-7859. [CrossRef]

16. Flores, M.; Muhl, S.; Huerta, L.; Andrade, E. The influence of the period size on the corrosion and the wear abrasion resistance of TiN/Ti multilayers. Surf. Coat. Technol. 2005, 200, 1315-1319. [CrossRef]

17. Ramos, A.S.; Vieira, M.T.; Serra, C. Ti/Al nanolayered thin films. J. Nanosci. Nanotechnol. 2009, 9, $3627-3632$. [CrossRef] [PubMed]

18. Wu, H.; Mayeshiba, T.; Morgan, D. High-throughput ab-initio dilute solute diffusion database. Sci. Data 2016, 3, 160054. [CrossRef] [PubMed]

19. Colgan, E.G. A review of thin-film aluminide formation. Mat. Sci. Rep. 1990, 5, 1-44. [CrossRef]

20. Rothhaar, U.; Oechsner, H.; Scheib, M.; Müller, R. Compositional and structural characterization of temperature-induced solid-state reactions in Al/Ni multilayers. Phys. Rev. B 2000, 61, 974-979. [CrossRef]

21. Kang, B.C.; Kim, H.Y.; Kwon, O.Y.; Hong, S.H. Bilayer thickness effects on nanoindentation behavior of Ag/Ni multilayers. Scripta Mater. 2007, 57, 703-706. [CrossRef]

(C) 2020 by the authors. Licensee MDPI, Basel, Switzerland. This article is an open access article distributed under the terms and conditions of the Creative Commons Attribution (CC BY) license (http://creativecommons.org/licenses/by/4.0/). 